\title{
DETERMINANTES DO ENDIVIDAMENTO - EVIDÊNCIA EMPÍRICA DAS PME DA REGIÃO ALENTEJO
}

\author{
DETERMINANTS OF INDEBTEDNESS - EMPIRICAL EVIDENCE OF SME \\ IN THE ALENTEJO REGION \\ DETERMINANTES DEL ENDEUDAMIENTO - EVIDENCIA EMPÍRICA DE \\ LAS PYME EN LA REGIÓN DEL ALENTEJO
}

\author{
Rosa Botelho (rosabotelho79@gmail.com)* \\ Maria Basílio (maria.basilio@ipbeja.pt)** \\ Carlos Borralho (cborralho@ipbeja.pt)***
}

\section{RESUMO}

O presente estudo teve como objetivo a análise da estrutura de capital das Pequenas e Médias Empresas - PME - da região do Alentejo, no período entre 2013 e 2016, num período de saída de uma crise económica profunda. Para a concretização desse objetivo, utilizou-se como variável dependente o endividamento, subdividido em curto prazo e médio/longo prazo. Já como variáveis independentes foram assumidos outros benefícios fiscais, o risco, a dimensão, a composição do ativo, a reputação, a rendibilidade do ativo e o crescimento. A metodologia de análise de dados utilizada foi a de regressão com dados em painel. Constata-se, neste estudo, que o endividamento é principalmente de curto prazo para as PME do Alentejo, resultado que vai ao encontro das evidências empíricas obtidas para a generalidade das PME portuguesas. Os resultados obtidos evidenciam ainda que a teoria que melhor explica a estrutura de capital é a teoria da pecking order. Em termos de implicações, os resultados parecem evidenciar que as PME da região Alentejo enfrentam dificuldades de acesso ao crédito, neste período de saída da crise. Estes resultados são importantes para os decisores políticos, sugerindo-se a adoção de medidas, como a criação de linhas especiais de crédito ou benefícios fiscais, que permitam mitigar eventuais dificuldades no acesso a fontes externas de financiamento.

Palavras Chave: estrutura de capital, endividamento, PME, Alentejo.

\section{ABSTRACT}

The present study aimed to analyse the capital structure of Small and Medium Enterprises - SME - of the Alentejo region, in the period between 2013 and 2016. To achieve this goal, debt was subdivided in short term and medium/long term and it was used as dependent variable. The independent variables were other tax benefits, risk, size, asset composition, reputation, asset profitability and growth. The methodology used was panel data regression. It is observed in this study that indebtedness is mainly short-term for Alentejo SME, a result that meets the empirical evidence obtained for the generality of Portuguese SME. The results obtained also show that the theory that best explains the capital structure is the theory of pecking order. In terms of implications, the results seem to show that SMEs in the Alentejo region face difficulties in accessing credit in this exit period 
from the crisis. These results are important for policy makers, suggesting the adoption of measures, such as the creation of special lines of credit or tax benefits, to mitigate any difficulties in accessing external sources of financing.

Keywords: capital structure, indebtedness, SME, Alentejo.

\section{RESUMEN}

El presente estudio tiene como objetivo analizar la estructura de capital de las Pequeñas y Medianas Empresas - PYMES - de la región del Alentejo, en el período comprendido entre 2013 y 2016. Para lograr este objetivo, la deuda se subdividió en corto plazo y medio/largo plazo y se utilizó como variable dependiente. Las variables independientes fueron otros beneficios fiscales, el riesgo, el tamaño, la composición de los activos, la reputación, la rentabilidad de los activos y el crecimiento. La metodología de análisis de datos utilizada fue la regresión con datos de panel. En este estudio se observa que el endeudamiento es principalmente a corto plazo para las PYME del Alentejo, resultado que cumple con la evidencia empírica obtenida para la generalidad de la PYME portuguesas. Los resultados obtenidos muestran también que la teoría que mejor explica la estructura de capital es el Modelo Jerárquico. En cuanto a las implicaciones, los resultados parecen mostrar que las PYME de la región de Alentejo enfrentan dificultades para acceder al crédito en este período de salida de la crisis. Estos resultados son importantes para los formuladores de políticas, sugiriendo la adopción de medidas, como la creación de líneas especiales de crédito o beneficios fiscales, que permitan mitigar las dificultades de acceso a fuentes externas de financiamiento.

Palabras clave: estructura de capital, endeudamiento, PYME, Alentejo.

* Mestre em Contabilidade e Finanças, ESTIG/Instituto Politécnico de Beja.

** Doutor em Gestão pelo ISEG / Universidade de Lisboa. Professora Adjunta da ESTIG/IPBeja.

*** Doutor em Gestão pela Universidade de Évora. Professor Adjunto Convidado da ESTIG/IPBeja.

Submitted: $7^{\text {th }}$ April 2020

Accepted: $12^{\text {th }}$ September 2020 


\section{INTRODUÇÃO}

A crise financeira e económica vivida na primeira década do século XXI, acarretou dificuldades na obtenção de financiamento por parte das PME portuguesas. Em muitos casos, estas empresas não conseguiram iniciar, desenvolver ou expandir as suas atividades por falta de capital, o que as levou a procurar recorrer a financiamento, situação nem sempre de fácil consecução (Correia, 2018).

O recurso ao financiamento externo condiciona a estrutura de capital (EC) de cada empresa e é uma decisão de primordial importância, pois afeta toda a sua atividade (Sibindi, 2016). Modigliani e Miller (1958) foram os precursores da teoria financeira sobre a EC. O seu trabalho constituiu uma importante referência académica, servindo de estímulo à investigação da temática, com o aparecimento de novas teorias, nomeadamente, a teoria da pecking order (Myers, 1984; e Myers \& Majluf, 1984), a teoria do trade-off (Kraus \& Litzenberger, 1973), a teoria de custo de agência (Jensen \& Meckling, 1976), entre outras. Consequentemente, estas teorias têm sido objeto de diferentes estudos empíricos, os quais testam a sua adequabilidade em múltiplos contextos.

As micro, pequenas e médias empresas representavam em 2018, 99,9\% das empresas não financeiras a operarem em Portugal (INE, 2020), ou seja, são a esmagadora maioria do tecido empresarial no nosso país, tal como ocorre a nível europeu (Eurostat, 2019). Estas empresas são fundamentais para o desenvolvimento económico e social de qualquer região ou país, dado o seu contributo importante em termos de criação de riqueza e de emprego. Em Portugal e com dados de 2018, tinham 3.193.340 pessoas ao serviço e geraram um valor acrescentado bruto (VAB) de 63.260 Milhões de Euros, o que representava $78,6 \%$ e $64,1 \%$ dos totais nacionais, respetivamente (INE, 2020).

Com dados do mesmo ano, no Alentejo, das 86.098 empresas não financeiras existentes, 86.054 são micro, pequenas e médias empresas (aproximadamente 100\%) e apenas 44 são consideradas grandes empresas (INE, 2020). Estas empresas representavam em 2017, 6,6\% do total nacional em termos de VAB e de emprego (INE, 2019).

Não obstante já existirem bastantes estudos centrados nas PME portuguesas (por exemplo, Pinho, 2013; Proença et al., 2014; Vieira \& Novo, 2010), estes não refletem a situação específica da região do Alentejo, dado que a esmagadora maioria dos estudos versam o país na sua globalidade ou refletem a realidade de algumas sub-regiões do país, as quais podem apresentar dinâmicas muito diferentes. Por este motivo, e dado o Alentejo ser, do ponto de vista geográfico, a maior região do país, interessa perceber se as PME desta região têm idêntico comportamento ao das restantes PME. Apenas Cardoso (2015) focou o seu estudo na EC das micro, pequenas e médias empresas da região Alentejo, utilizando dados de 2006 a 2013. No entanto, este autor utilizou uma amostra considerando para além das PME, também as micro empresas (com menos de 10 trabalhadores).

Face ao exposto, este artigo tem como objetivo analisar a EC das PME da região Alentejo, identificar qual a teoria preponderante nas decisões de financiamento, bem como, estudar os determinantes do endividamento. Este estudo foi realizado utilizando modelos de dados em painel. A amostra foi constituída por 443 PME, utilizando dados dos anos 2013 a 2016, obtidos a partir da base de dados SABI (Sistema de Análise de Balanços Ibéricos). A principal contribuição deste trabalho reside na análise de apenas pequenas e médias empresas (PME) dadas as especificidades destas empresas e que as diferenciam das grandes empresas (Osteryoung et al., 1992; Pascoal, 2008) e das microempresas que regra geral, são de cariz 
familiar e apresentam dificuldades de acesso às fontes de financiamento (Rocha, 2000), num período de saída de uma crise económica profunda (2013 a 2016).

O presente artigo é estruturado em quatro secções, para além da introdução. Na secção seguinte, intitulada Revisão da Literatura, é apresentada uma breve revisão das teorias da EC e, no final, referem-se alguns trabalhos empíricos relevantes que abordam a EC na ótica das PME. Nas secções seguintes apresentam-se as hipóteses a testar e a metodologia. Já na secção 4, analisam-se e discutem-se os resultados obtidos e, por fim, na última secção, são apresentadas as conclusões e limitações da investigação realizada.

\section{REVISÃO DA LITERATURA}

A EC é a forma como a empresa combina a utilização do capital próprio e do capital alheio para financiar os seus ativos (Pinho \& Tavares, 2005). As empresas, ao escolherem a forma de se financiarem devem ter como preocupação base congregar as fontes que Ihes possibilitem atingir uma EC ótima (Matias \& Serrasqueiro, 2017). Segundo Menezes (2012, p. 364) "a estrutura ótima de capitais é a que minimiza o custo do capital e, simultaneamente, maximiza o valor da empresa".

Muito se tem estudado na procura de uma estrutura ótima de capital, principalmente desde a publicação do trabalho de Modigliani \& Miller (1958). No entanto ainda não existe consenso em relação a existência de uma estrutura ótima e aos fatores que a determinam. Também por isso, diversas correntes teóricas têm sido desenvolvidas ao longo do tempo.

A teoria tradicional surge com Durand (1952), que defendia a existência de uma combinação ótima de capital próprio e alheio, possibilitando assim, minimizar o custo de capital médio ponderado e maximizar o valor de mercado da empresa. Modigliani \& Miller (1958) vieram defender o princípio da irrelevância da EC, isto é, empresas idênticas têm o mesmo valor, não obstante o facto de se financiarem através de capitais próprios ou capitais alheios (recurso à dívida). Assim a EC é irrelevante na determinação do valor da empresa e as decisões de financiamento são insignificantes em mercados perfeitos.

Mais tarde, Modigliani \& Miller (1963) vieram colmatar algumas das limitações apontadas à sua teoria original, ao considerarem os efeitos dos impostos. Isto porque existem vantagens na utilização de capital alheio em comparação com o capital próprio, pois os juros são dedutíveis em termos fiscais originando uma poupança de imposto, e pelo contrário, os dividendos não originam qualquer poupança de imposto. Para Modigliani \& Miller (1963), o valor de mercado da empresa endividada é igual ao de uma empresa não endividada adicionado do benefício fiscal que o endividamento proporciona. O que nos leva à seguinte questão: deve uma empresa endividar-se a 100\%?

Uma das críticas feitas ao seu trabalho, foi o facto de não considerarem os custos de falência (Sibindi, 2016). Estes custos surgem quando os compromissos para com os credores não são satisfeitos ou são-no com dificuldades (custos legais, administrativos e derivados das dificuldades de funcionamento). Enquanto este processo decorre, o valor da empresa vai diminuindo e surgem conflitos de interesse entre os diferentes agentes interessados na empresa, tais como, acionistas, credores e gestores (Jensen \& Meckling, 1976; Diamond, 1989).

Assim, a ponderação do efeito fiscal resultante do uso de dívida como forma de financiamento e a inclusão do efeito dos custos de falência sustentaram o surgimento da teoria do trade-off 
(Kraus \& Litzenberger, 1973). Esta teoria baseia-se na ideia de que, se por um lado, o endividamento pode trazer vantagens para a empresa sob a forma de benefícios fiscais, por outro, pode ser desvantajoso no respeitante aos custos relacionados com a falência da empresa. Existe maior probabilidade de incorrer em falência com o aumento do grau de endividamento. A combinação das duas variáveis poupança fiscal e custos de falência resulta numa combinação ótima entre capital próprio e alheio, maximizando o valor da empresa (Serrasqueiro, Armada, \& Nunes, 2011).

Também Jensen \& Meckling (1976) abordaram os conflitos que surgem no interior das empresas, particularmente, os ocorridos entre acionistas, gestores e credores. Quando os interesses do gestor não são os mesmos que os do acionista e o gestor tenta satisfazer os seus próprios interesses, antes de respeitar o compromisso que tinha assumido com os acionistas, surgem os chamados custos de agência. Para estes mesmos autores, existem dois tipos de conflitos de agência: o conflito que surge entre sócios/acionistas e gestores, que origina o chamado custo de agência do capital próprio e, os conflitos que surgem entre os credores e os acionistas, o qual se denomina de custo de agência da dívida. A empresa vai atingir a estrutura ótima de capitais quando o montante total de custos de agência (da dívida e do capital próprio) for mínimo. No caso das PME, apenas os custos de agência verificados entre credores e sócios (proprietários) podem ser particularmente significativos, visto que na maioria das vezes a propriedade é coincidente com a gestão neste tipo de empresas (Sogorb-Mira, 2005).

Anos mais tarde Myers \& Majluf (1984) desenvolveram a teoria da informação assimétrica. Neste modelo, assume-se que os gestores das empresas detêm informação sobre as empresas, que os investidores não possuem. Nem toda a informação é do conhecimento de todos os intervenientes, isto é, os gestores que detêm informação privilegiada emitirão títulos de risco apenas quando estes estiverem sobrevalorizados e voltarão a comprar os títulos se estes se subvalorizarem (Alcarva, 2017). A assimetria de informação deu origem a duas grandes correntes: a teoria da pecking ordere a teoria da sinalização (Gomes, 2012).

Na Pecking Order Theory as empresas, para contornarem os problemas resultantes da assimetria de informação, recorrem ao financiamento dos seus projetos, através de outras formas de financiamento que existem no mercado. Para tal, procede-se à hierarquização das escolhas de financiamento (teoria das preferências hierárquicas). As empresas primeiro recorrem ao financiamento interno, ou seja, aos fundos gerados internamente, o chamado autofinanciamento. Só depois recorrem ao financiamento externo. Por último, optam pela emissão de novas ações, abrindo assim, o capiłal a investidores externos. Isto com o objetivo de obter financiamento ao menor custo possível (Myers, 1984).

Uma outra abordagem é dada pela teoria da sinalização. Nesta abordagem assume-se que os gestores possuem informações sobre a empresa, mais detalhadas e rigorosas, do que as informações possuídas pelos investidores externos. Sendo assim, todas as ações dos gestores serão avaliadas pelos investidores com o objetivo de obterem informações relevantes para as suas tomadas de decisão (Leland \& Pyle, 1977; Ross, 1977). Para Ross (1977) a forma como a estrutura de capitais de uma empresa é constituída, emite para o mercado um sinal acerca do tipo de empresa. Um aumento do endividamento evidencia que a empresa goza de boa saúde financeira, pois tem uma boa capacidade de gerar fundos e solver compromissos. Por seu lado, se uma empresa apresentar um baixo grau de endividamento realça a possibilidade desta se encontrar numa situação financeira fragilizada. Leland \& Pyle (1977) realçam que, quando os próprios gestores investem no capital da empresa esse é um sinal positivo, pois se eles, que detêm informação privilegiada, investem no projeto é porque confiam nele e o consideram bom. No contexto das PME, esta teoria tem pouca aplicabilidade visto qua a maioria das empresas não tem acesso ao mercado de capitais (Sogorb-Mira, 2005). 
Efetuou-se uma breve apresentação das diferentes teorias que procuram explicar a EC, pelo que importa agora destacar alguns estudos empíricos sobre o tema. Em Portugal, alguns trabalhos abordam um setor específico, como, por exemplo, Pacheco \& Tavares (2015) que se focam nas PME do setor do calçado ou Matias, Salsa \& Afonso (2018) que se centram nas empresas do setor da hotelaria. Outros autores centram a sua análise numa região específica, por exemplo Raposo (2013) analisa a EC das PME do distrito de Castelo Branco. Outros ainda, procuraram explicar os efeitos da internacionalização na EC das empresas portuguesas (Pacheco, 2016; Silva \& Lopes, 2018).

Seguidamente são detalhados alguns estudos empíricos focados nas micro, pequenas e médias empresas, onde se apresentam de forma resumida, as variáveis utilizadas, os resultados e as conclusões obtidas (ordenados cronologicamente). Na Tabela 1 apresentamse alguns trabalhos focados em empresas portuguesas e na Tabela 2, estudos que versam sobre PME estrangeiras.

Da análise destes trabalhos conclui-se que a maioria utiliza, como metodologia modelos de regressão linear múltipla, mas principalmente modelos de dados em painel. As bases de dados maioritariamente usadas são a SABI e a AMADEUS. No que respeita aos determinantes da EC, as escolhas dos vários autores são muito semelhantes, sendo que, como variáveis dependentes, as mais utilizadas são a utilização simultânea do endividamento total, o endividamento de curto prazo e o endividamento de médio e longo prazo. Quanto às variáveis independentes, sobressaem, pela sua utilização, as seguintes: outros benefícios fiscais para além da dívida; dimensão; composição do ativo; rendibilidade; crescimento e risco. Por sua vez, as teorias mais abordadas e testadas são a Pecking Ordere Trade-off. Entre estas, aquela que maior número de vezes encontrou correspondência empírica foi a da Pecking Order. Existem contudo estudos, onde foi encontrada evidência da utilização de ambas as teorias. 


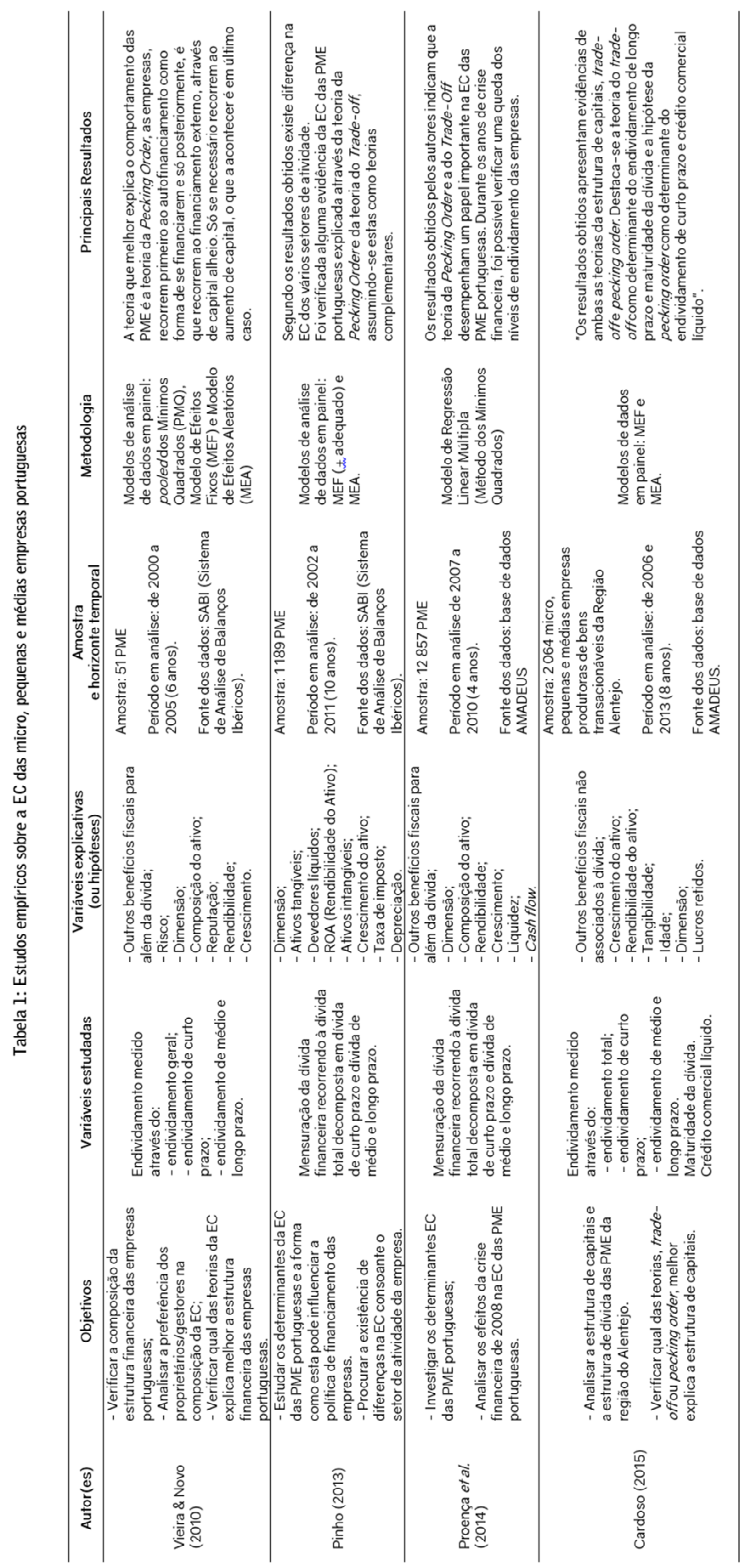


$E G|T A N| A S C|E N C| A$

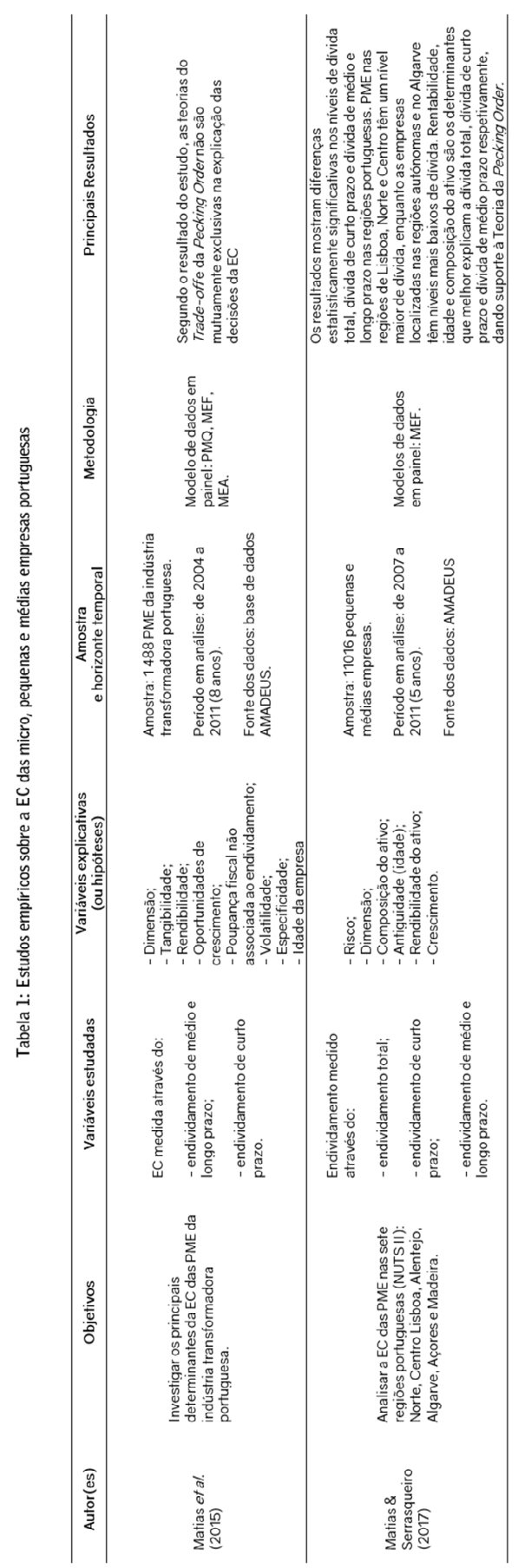




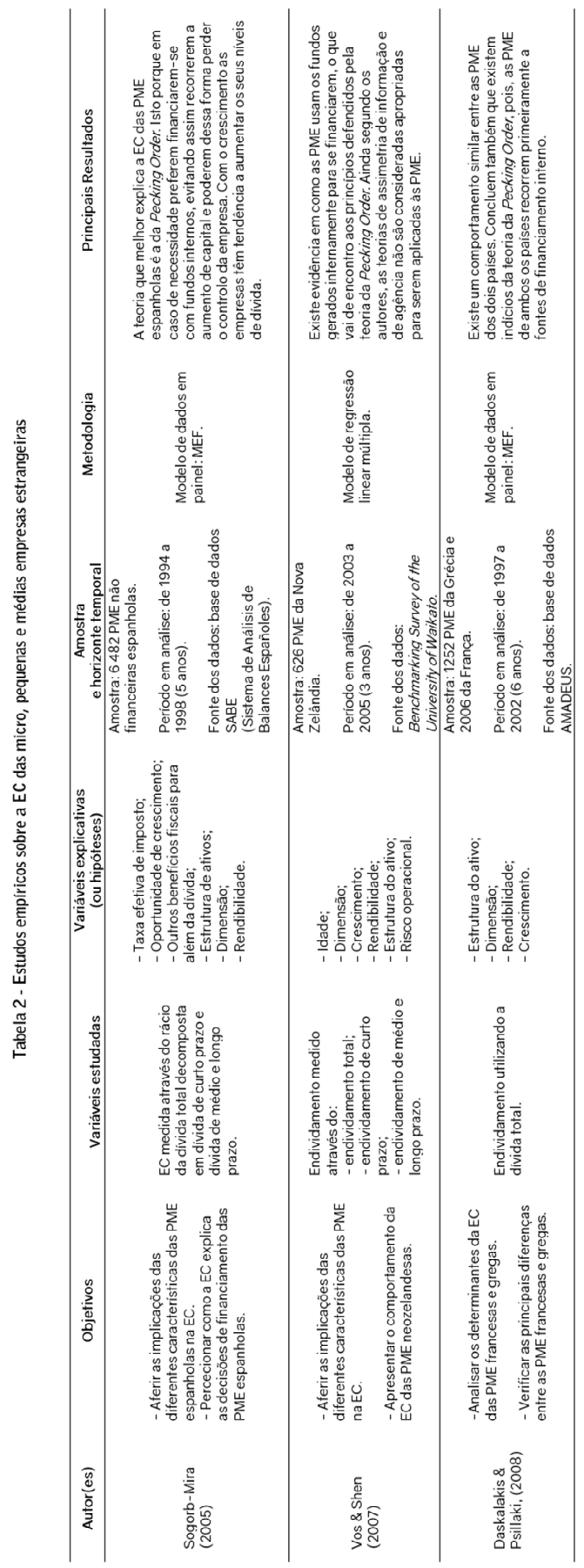




\section{HIPÓTESES}

O presente estudo visa analisar o endividamento das PME da região Alentejo. Como variáveis dependentes utilizou-se o endividamento total (EG), subdividido em endividamento de curto prazo (ECP) e endividamento de médio e longo prazo (EMLP).

As hipóteses a testar derivam da literatura e considera-se o mesmo efeito esperado nos três rácios de endividamento (EG, ECP e o EMLP).

\section{- Outros Benefícios Fiscais para além da dívida (OBF)}

Os estudos de Gama (2000), Kim \& Sorensen (1986), Júnior (2012) e Vieira \& Novo (2010) apresentam uma relação negativa entre o endividamento e os OBF. As empresas com um nível de benefícios fiscais menor mas, por sua vez, com uma elevada rendibilidade tendem a recorrer mais ao endividamento, para assim poderem utilizar os juros da dívida como benefício fiscal estando em consonância com a teoria do trade off. Conforme referido por Júnior (2012), os encargos associados à dívida podem constituir uma redução da matéria coletável. Quanto maior for o valor de OBF, menor será o nível de endividamento da empresa e também menor será a necessidade desta se endividar para conseguir ter uma eficaz gestão fiscal. A relação esperada entre OBF e o endividamento é uma relação negativa:

Hipótese 1 (H1): Existe uma relação negativa entre o nível de outros benefícios fiscais para além da dívida e o endividamento, ou seja, quanto maior o nível de outros benefícios fiscais para além da dívida, menor tende a ser o nível de endividamento registado pela empresa.

- $\quad$ Risco (RI)

O relacionamento do risco com o endividamento é estudado por vários autores. No entanto, as conclusões obtidas são discordantes. Enquanto uns encontram uma relação positiva, tal como Kim \& Sorensen (1986) e Jorge \& Armada (2001), outros encontram uma relação negativa, tal como Bradley, Jarrell, \& Kim (1984) e Serrasqueiro et al. (2011). Segundo Vieira \& Novo (2010) um dos motivos para a existência de tal discordância relaciona-se com a dificuldade em estabelecer parâmetros para calcular o risco, dado que os custos de insolvência financeira são de complicada avaliação. Neste trabalho, assim como para Vieira \& Novo (2010), a relação esperada entre o risco e o endividamento é negativa. Será utilizado o coeficiente de Pearson das vendas, como proxydo risco, o qual é obtido pelo rácio entre o desvio padrão das vendas e a média das vendas (Esperança et al., 2003):

Hipótese 2 (H2): O grau de endividamento está inversamente relacionado com o risco do negócio.

\section{- Dimensão (DIM)}

Jensen \& Meckling (1976), no seu contributo para o desenvolvimento da teoria da agência, sugerem uma relação positiva entre a dimensão e o endividamento, pois as grandes empresas possuem mais custos de agência do que as de menor dimensão. Também para Titman \& Wessels (1988), se a empresa tiver uma grande dimensão a sua capacidade de endividamento será maior. Maiores empresas tem maior facilidade de acesso ao crédito e consequentemente menores custos de financiamento. Do mesmo modo, Rogão (2006), Serrasqueiro, et al. (2011) e 
Santos (2016) referem a existência de uma relação positiva entre a dimensão e o endividamento. Já para Ribeiro (2015) a relação existente entre as duas variáveis é negativa, pois quanto maior for a empresa, maior capacidade terá de gerar lucros e de se financiar com recursos internos. Neste trabalho, espera-se uma relação positiva entre a dimensão e o endividamento:

Hipótese 3 (H3): O endividamento aumenta com a dimensão da empresa.

- Composição do Ativo (CA)

Para Titman \& Wessels (1988) e Sibindi (2016) os ativos fixos tangíveis podem ser dados como garantia no caso de financiamentos o que reduz os custos de agência e também os custos de falência. Estes ativos servem como collaterale constituem uma mais-valia que poderá ser usada na negociação com os credores:

Hipótese 4 (H4): Quanto maior for o valor de garantia dos ativos fixos tangíveis da empresa, maior será o rácio de endividamento.

- Reputação (RE)

Empresas com uma boa reputação no mercado terão um maior poder negocial junto dos credores, pelo que será esperada uma relação positiva entre o endividamento e a reputação. (Gama, 2000 e Matias \& Serrasqueiro, 2017). Um indicador de bom desempenho de uma empresa é o número de anos que esta resista no mercado, isto é, empresas que estejam no mercado há mais tempo, à partida terão uma melhor reputação que empresas mais novas e terão maior facilidade de acesso a fontes de financiamento externas. Utilizando como proxyda reputação, o grau de antiguidade da empresa, tem-se:

Hipótese 5 (H5): O endividamento aumenta com o aumento da reputação da empresa no mercado, medido pela sua antiguidade.

- Rendibilidade do Ativo (RA)

Ross (1977) defende a existência de uma relação positiva entre o endividamento e a rendibilidade baseado na teoria da sinalização, uma vez que, os credores têm tendência a financiar empresas que apresentem níveis de rendibilidade mais estáveis. Por sua vez, a teoria da pecking order de Myers (1984) e Myers \& Majluf (1984), prevê que a relação entre o endividamento e a rendibilidade seja negativa, pois as empresas mais rentáveis têm propensão a financiar-se com resultados retidos.

A hipótese em estudo foi enunciada tendo em conta a teoria da pecking order, sendo assim de esperar uma relação negativa entre o endividamento e a rendibilidade, tal como para Sogorb-Mira (2005):

Hipótese 6 (H6): Quanto maior for a rendibilidade da empresa, menor é o seu grau de endividamento.

- Crescimento (CRE)

Ao existir uma oportunidade de crescimento e se o financiamento interno não for suficiente, as empresas têm que recorrer a financiamento externo, aumentando os seus níveis de endividamento. Tal como para Gama (2000) e Proença et al. (2014), espera-se que a relação a obter entre o endividamento e o crescimento seja positiva, o que permitirá aferir a hierarquia das fontes de financiamento:

Hipótese 7 (H7): O aumento do nível de endividamento está positivamente associado ao nível de investimentos recentes. 


\section{METODOLOGIA}

No âmbito ontológico a presente investigação assume um postulado realista. Já ao nível epistemológico, entendido enquanto doutrina dos fundamentos e métodos, posiciona-se no domínio positivista, com investigadores não participantes. Já ao ser considerado o âmbito metodológico é quantitativa e avoca uma abordagem hipotético-dedutiva (Cervo e Bervian, 1983; Barañano, 2004; Coutinho, 2014).

Aclarado o posicionamento ontológico, epistemológico e metodológico, é seguidamente detalhada a amostra, bem como identificadas as variáveis objeto de análise, tal como a técnica estatística usada.

\subsection{Amostra}

A definição de PME utilizada neste estudo, é a que consta da Recomendação da Comissão 2003/361/CE de 6 de maio de 2003, que carateriza as empresas de acordo com os seguintes critérios: número de trabalhadores, volume de negócios e total do balanço anual.
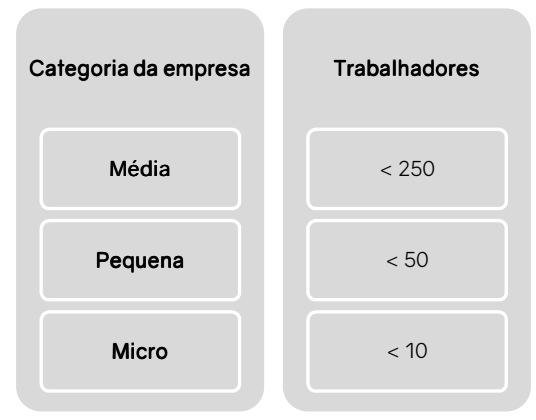

Figura 1 - Definição de PME
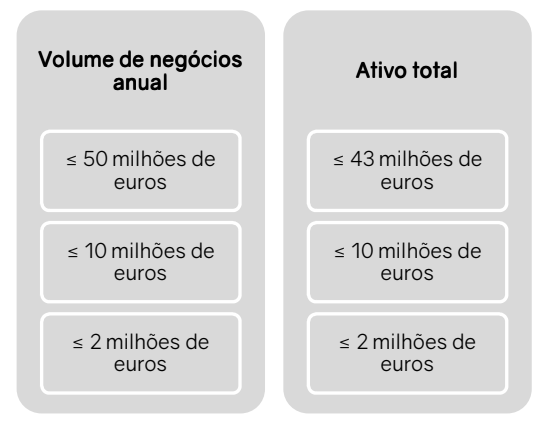

Fonte: Elaboração própria com base na Recomendação da Comissão 2003/361/CE.

Considerou-se pertinente não considerar as microempresas, pois apresentam várias particularidades. São empresas de cariz familiar e que normalmente apresentam maiores dificuldades de acesso às fontes de financiamento. De acordo com Rocha (2000), as empresas de pequena dimensão apresentam vários problemas que são enfatizados nas microempresas, entre eles, a sobreposição frequente entre a propriedade e a gestão (são normalmente geridas pelos proprietários), conflitos de agência enfatizados entre credores/proprietários, maiores custos de transação e maiores custos de falência.

A análise da evolução do endividamento das empresas não financeiras em Portugal, ao longo dos últimos anos, reforçou esta escolha. O Gráfico 1 mostra essa evolução, desde 2010 a 2018. 


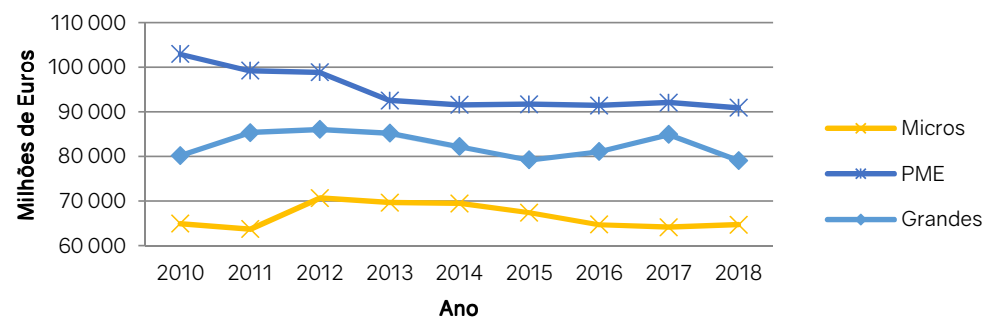

Gráfico 1 - Endividamento das empresas privadas (2010-2018)

Fonte: PORDATA (Banco de Portugal - Endividamento do setor não financeiro).

Por tipo de empresas, verifica-se que as PME apresentam o maior valor de endividamento ao longo dos anos. No horizonte temporal aqui considerado, 2013 a 2016, registam um valor aproximadamente constante, com uma ligeira tendência de descida (de $92546 \mathrm{M} €$ em 2013 para $91418 \mathrm{M} €$ em 2016).

Com o objetivo de estudar a EC das PME da região do Alentejo, foram consideradas as pequenas e médias empresas pertencentes aos 58 municípios desta região, com prestação de contas em Portugal.

Foram ainda realizados ajustamentos: foram retiradas as empresas que apresentavam valores de Capital Próprio negativos (tecnicamente em situação de falência) e empresas que apresentavam valores inconsistentes ou para as quais não existia a totalidade dos dados necessários. No final, obteve-se uma amostra de 443 empresas de acordo com o período escolhido para análise (2013 a 2016). Trata-se de uma amostra não probabilística por conveniência (Gil, 2008), visto que está subjacente à disponibilidade dos dados na base de dados $\mathrm{SABI}$ e à reunião dos critérios de seleção acima definidos.

\subsection{Variáveis Dependentes}

O presente estudo visa compreender a relação entre o endividamento das PME na região do Alentejo e as diferentes variáveis independentes. Será considerado o endividamento total e subdividido em curto prazo e médio/longo prazo, para identificar possíveis diferenças. A Tabela 3 apresenta as variáveis dependentes.

Tabela 3 - Variáveis Dependentes.

\begin{tabular}{lll}
\hline \multicolumn{1}{c}{ Variável } & \multicolumn{1}{c}{ Definição } & Fórmula de Cálculo \\
\hline EG & Endividamento Geral & $\frac{\text { Capital Alheio }}{\text { Ativo Total Líquido }}$ \\
\hline ECP & Endividamento de Curto Prazo & $\frac{\text { Capital Alheio CP }}{\text { Ativo Total Líquido }}$ \\
\hline EMLP & Endividamento de Médio e Longo Prazo & $\frac{\text { Capital Alheio MLP }}{\text { Ativo Total Líquido }}$ \\
\hline Fonte: Elaboracão própria &
\end{tabular}

Fonte: Elaboração própria. 


\subsection{Variáveis Independentes}

Enunciadas as hipóteses na seção 2, importa agora relacionar essas hipóteses com as variáveis objeto de estudo. A Tabela 4 apresenta assim um resumo das variáveis independentes, bem como, a fórmula de cálculo e o sinal esperado para cada hipótese de investigação.

Tabela 4 - Variáveis Independentes.

\begin{tabular}{|c|c|c|c|c|}
\hline Hip. & Variável & Definição & Fórmula de Cálculo & $\begin{array}{c}\text { Sinal } \\
\text { Esperado }\end{array}$ \\
\hline H1 & OBF & $\begin{array}{l}\text { Outros Benefícios Fiscais } \\
\text { para além da dívida }\end{array}$ & $\frac{\text { Depreciações do exercício }}{\text { Ativo Total Líquido }}$ & - \\
\hline $\mathrm{H} 2$ & RI & Risco & $\begin{array}{l}\text { Coeficiente de variação (Pearson) das } \\
\text { vendas }=\frac{\text { Desvio Paddrao vendas }}{\text { Média das Vendas }}\end{array}$ & - \\
\hline $\mathrm{H3}$ & DIM & Dimensão & Logaritmo do Ativo Total Líquido & + \\
\hline $\mathrm{H} 4$ & $\mathrm{CA}$ & Composição do Ativo & $\frac{\text { Ativos Fixos Tangíveis Líquidos }}{\text { Ativo Total Líquido }}$ & + \\
\hline $\mathrm{H} 5$ & RE & Repułação & Logaritmo do número de dias de atividade & + \\
\hline H6 & RA & Rendibilidade do Ativo & $\frac{\text { Resultados Antes Impostos (RAI) }}{\text { Ativo Total Líquido }}$ & - \\
\hline H7 & CRE & $\begin{array}{l}\text { Taxa de Crescimento do } \\
\text { Ativo }\end{array}$ & $\frac{\text { Total Ativo }_{\text {Ano } N}-\text { Total Ativo }_{\text {Ano } N-1}}{\text { Total Ativo }_{\text {Ano } N-1}}$ & - \\
\hline
\end{tabular}

Fonte: Elaboração própria.

Como variáveis de controlo, foram ainda consideradas time-dummies para capturar eventuais efeitos associados ao tempo, seguindo Wooldridge (2015).

\subsection{Estimação e Especificação do Modelo}

Foi usada regressão com dados em painel (Wooldridge, 2015). A utilização de dados em painel apresenta várias vantagens relativamente aos modelos para dados seccionais, nomeadamente, a obtenção de estatísticas mais precisas e o aumento da potência dos testes estatísticos, permitem a compreensão da relação entre as variáveis em estudo ao longo do tempo e ainda, relevam a heterogeneidade individual (Marques, 2000; Matias et al., 2015).

As observações são referentes às mesmas empresas durante quatro anos, obtendo-se um painel balanceado. O modelo é o seguinte:

$$
Y_{i, t}=\beta_{0}+\sum_{k=1}^{10} \beta_{k} X_{k i, t}+\varepsilon_{i, t}
$$

Onde:

$Y_{i, t}=$ Medida do endividamento da empresa i no ano $t$, sendo estimadas três regressões para o EG, ECP e EMLP;

$$
\begin{aligned}
& \beta_{0}=\text { Constante (parâmetro a estimar); } \\
& \left.\beta_{k}=\text { Parâmetros a estimar pelo modelo (com } \mathrm{k}=1,2, \ldots 10\right) ; \\
& X=\text { Vetor das variáveis explicativas que inclui os fatores já referidos; } \\
& \varepsilon_{i, t}=\text { Erro aleatório. }
\end{aligned}
$$

Foram testados três modelos: o pooled dos mínimos quadrados (PMQ), o modelo de efeitos fixos (MEF) e o modelo de efeitos aleatórios (MEA). O MEF é um modelo "cujos coeficientes 
podem variar de indivíduo para indivíduo ou no tempo, ainda que permaneçam como constantes fixas, logo, não aleatórias" (Marques, 2000, p. 9). Por sua vez o MEA "pressupõe que o comportamento específico dos indivíduos e períodos de tempo é desconhecido, não podendo ser observado, nem medido" (Marques, 2000, p. 13).

Os modelos foram estimados com erros-padrão robustos e cluster robust para o $\mathrm{PMQ}$, para controlar a heterocedasticidade. No PMQ, cada empresa é considerada um cluster, e naturalmente as observações de uma empresa registadas num ano, estarão relacionadas com as observações do ano anterior dessa mesma empresa. Assim é possivel relaxar o pressuposto de independência entre as observações, apenas se exigindo que as observações não estejam correlacionadas entre empresas.

Procurou-se escolher o modelo mais adequado recorrendo ao teste $\mathrm{F}$ para Efeitos Fixos, ao teste Breusch-Pagan Lagrangian multipliere ao teste de Hausman, tendo a escolha recaído no MEF, considerando um nível de significância de 1\%. Por simplificação apenas se apresentam os resultados obtidos com este modelo, estando disponíveis no apêndice A os resultados obtidos com os três modelos e os valores dos testes realizados.

\section{RESULTADOS EMPÍRICOS E DISCUSSÃO}

Os resultados foram obtidos através do software estatístico STATA 14. Numa primeira fase, apresentam-se as estatísticas descritivas e a matriz de correlações entre as variáveis independentes. Seguidamente, efetua-se a análise e discussão dos resultados das regressões obtidas pelo MEF.

\subsection{Descrição da amostra}

A tabela seguinte (Tabela 5) mostra as estatísticas descritivas para todas as variáveis em estudo.

Tabela 5 - Resumo das Estatísticas Descritivas.

\begin{tabular}{lcccc}
\hline \multicolumn{1}{c}{ Variáveis } & Média & Desvio Padrão & Mínimo & Máximo \\
\hline EG & 0,5799 & 0,2223 & 0,0310 & 0,9995 \\
\hline ECP & 0,4099 & 0,2088 & 0,0213 & 0,9941 \\
\hline EMLP & 0,1700 & 0,1751 & 0,0000 & 0,7835 \\
\hline OBF & 0,0389 & 0,0342 & 0,0000 & 0,2654 \\
\hline RI & 0,1943 & 0,1798 & 0,0026 & 1,9450 \\
\hline DIM & 3,7178 & 0,3641 & 2,7351 & 5,2775 \\
\hline CA & 0,3006 & 0,2196 & 0,0007 & 0,9793 \\
\hline RE & 3,8584 & 0,2608 & 3,0667 & 4,5669 \\
\hline RA & 0,0411 & 0,0819 & $-0,4457$ & 0,5583 \\
\hline CRE & 0,0730 & 0,2540 & $-0,7516$ & 5,0525 \\
\hline
\end{tabular}

Fonte: Elaboração própria com base nos resultados obtidos pelo STATA.

Pela análise dos valores acima, pode-se constatar a existência de empresas com um nível de endividamento total e de curto prazo, muito próximo dos 100\%, o que significa que estas empresas têm uma situação económica muito débil. Em termos médios, o nível de EG das 
empresas em análise, relativo aos anos de 2013 a 2016, situa-se nos 58\%. Quanto ao ECP, este situa-se nos $41 \%$ e o EMLP nos $17 \%$. Como seria de esperar, as PME da região Alentejo são bastante mais dependentes do endividamento de curto prazo, de forma similar ao que se regista no resto do país. Os valores obtidos para os diferentes tipos de endividamento estão em linha com os resultados de outros autores, como por exemplo Gama (2000), Vieira \& Novo (2010), Proença et al. (2014) ou Serrasqueiro et al. (2016), que realizaram estudos com PME portuguesas. O Gráfico 2 mostra que as várias variáveis referentes ao endividamento, ao longo dos anos em estudo, mantêm uma grande estabilidade nos valores médios.

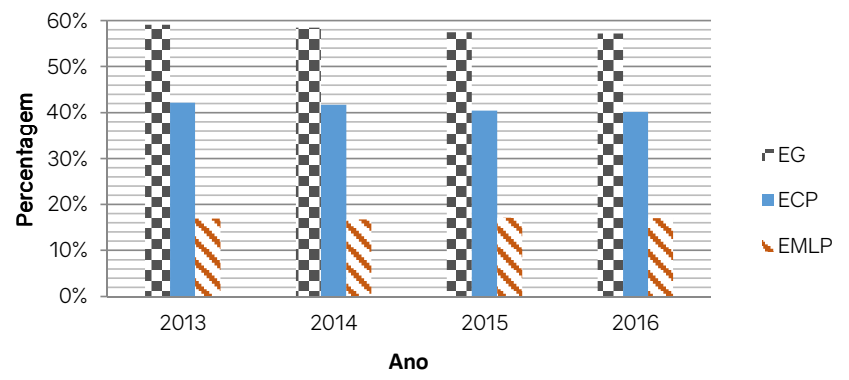

Gráfico 2 - Endividamento Médio das PME da Região Alentejo (2013-2016).

Fonte: Elaboração própria.

O desvio padrão observado, para a maioria das variáveis, é inferior à média, o que significa que as PME que fazem parte deste estudo terão indicadores financeiros bastante idênticos. Seguidamente será analisada a matriz de correlação (Tabela 6) das variáveis independentes, com o objetivo de identificar possíveis problemas de multicolinearidade entre elas.

Tabela 6 - Matriz Correlação de Pearson para as variáveis independentes.

\begin{tabular}{|c|c|c|c|c|c|c|c|}
\hline Variáveis & OBF & RI & DIM & $\mathrm{CA}$ & RE & RA & CRE \\
\hline OBF & 1,000 & & & & & & \\
\hline RI & $-0,035$ & 1,000 & & & & & \\
\hline DIM & 0,017 & $-0,039$ & 1,000 & & & & \\
\hline $\mathrm{CA}$ & $0,447^{* *}$ & $-0,037$ & $0,217^{* *}$ & 1,000 & & & \\
\hline $\mathrm{RE}$ & $-0,226^{* *}$ & $-0,200^{* *}$ & $0,147^{* *}$ & $-0,091^{* *}$ & 1,000 & & \\
\hline $\mathrm{RA}$ & $0,086^{* *}$ & $-0,062^{* *}$ & $-0,048^{*}$ & $-0,145^{* *}$ & $-0,117^{* *}$ & 1,000 & \\
\hline CRE & $-0,018$ & $0,176^{* *}$ & 0,028 & $-0,060^{*}$ & $-0,135^{* *}$ & $0,159^{* *}$ & 1,000 \\
\hline
\end{tabular}

Nota: ${ }^{* *},{ }^{*}$ - Representa um nível de significância de $1 \%$, e de $5 \%$, respetivamente.

Fonte: Elaboração própria com base nos resultados obtidos pelo STATA.

Da análise realizada à matriz de correlação, verifica-se existir de uma maneira geral um baixo grau de correlação entre as variáveis independentes, com exceção da correlação entre a variável CA e OBF, que apresenta um valor moderado, pelo que não se coloca em causa o problema da multicolinearidade. Para se confirmar a não existência de problemas, recorreuse adicionalmente ao indicador VIF ( Variance Inflation Factor). De acordo com Marôco (2011) valores de VIF superiores a 5 , indicam problemas com a estimação do modelo devido à 
presença de multicolinearidade nas variáveis independentes. O valor mais alto identificado foi de 1,38 referente à variável CA (composição do ativo), com um valor médio de VIF de 1,18, confirmando assim a inexistência de problemas.

\subsection{Determinantes do endividamento}

A Tabela 7 apresenta os resultados das regressões para cada variável dependente, utilizando o MEF. Uma análise preliminar realizada demonstrou que nem o PMQ nem o MEA eram considerados ajustados (Park, 2011). Resultados detalhados constam no Apêndice A.

Tabela 7 - Resultados da regressão (MEF).

\begin{tabular}{|c|c|c|c|c|c|c|}
\hline \multirow[b]{2}{*}{ Modelo: MEF } & \multicolumn{2}{|c|}{ EG } & \multicolumn{2}{|c|}{ ECP } & \multicolumn{2}{|c|}{ EMLP } \\
\hline & Coef. & $\begin{array}{c}\text { Erro- } \\
\text { Padrão } \\
\text { Robusto }\end{array}$ & Coef. & $\begin{array}{c}\text { Erro- } \\
\text { Padrão } \\
\text { Robusto }\end{array}$ & Coef. & $\begin{array}{c}\text { Erro- } \\
\text { Padrão } \\
\text { Robusto }\end{array}$ \\
\hline OBF & 0,145 & 0,235 & $-0,013$ & 0,412 & 0,158 & 0,332 \\
\hline RI & 0,010 & 0,037 & 0,022 & 0,043 & $-0,012$ & 0,045 \\
\hline DIM & $0,282^{* * *}$ & 0,063 & $0,153^{* *}$ & 0,074 & $0,129 * * *$ & 0,045 \\
\hline $\mathrm{CA}$ & $-0,028$ & 0,060 & $-0,174^{* *}$ & 0,079 & $0,147^{* *}$ & 0,059 \\
\hline $\mathrm{RE}$ & $-0,394^{* *}$ & 0,167 & $-0,191$ & 0,169 & $-0,203$ & 0,170 \\
\hline RA & $-0,358^{* * *}$ & 0,071 & $-0,115$ & 0,076 & $-0,243^{* * *}$ & 0,064 \\
\hline CRE & $0,030^{*}$ & 0,016 & 0,035 & 0,029 & $-0,005$ & 0,019 \\
\hline d_2014 & $-0,001$ & 0,005 & $-0,003$ & 0,006 & 0,001 & 0,005 \\
\hline d_2015 & $-0,005$ & 0,008 & $-0,013$ & 0,010 & 0,008 & 0,009 \\
\hline d_2016 & $-0,006$ & 0,012 & $-0,015$ & 0,014 & 0,009 & 0,013 \\
\hline constante & $1,069^{*}$ & 0,586 & 0,637 & 0,654 & 0,432 & 0,665 \\
\hline Observações (N) & \multicolumn{2}{|c|}{1772} & \multicolumn{2}{|c|}{1772} & \multicolumn{2}{|c|}{1772} \\
\hline R'2 Ajustado & \multicolumn{2}{|c|}{0,9220} & \multicolumn{2}{|c|}{0,8231} & \multicolumn{2}{|c|}{0,7934} \\
\hline Hausman Test & \multicolumn{2}{|c|}{$103,29 * * *$} & \multicolumn{2}{|c|}{$49,82^{* * *}$} & \multicolumn{2}{|c|}{$17,54^{* * *}$} \\
\hline
\end{tabular}

Fonte: Elaboração própria com base nos resultados obtidos pelo STATA.

As variáveis que são determinantes para o rácio do endividamento geral (EG) são a DIM (dimensão), RE (reputação) e a RA (rendibilidade do ativo) e CRE (taxa de crescimento do Ativo). Para explicar o endividamento de curto prazo (ECP) temos como variáveis significativas DIM (dimensão) e a CA (composição do ativo). Por fim, para explicar o endividamento de médio e longo prazo (EMLP) temos as variáveis DIM (dimensão), CA (composição do ativo) e RA (rendibilidade do ativo).

Verificou-se ainda que as time-dummies não são estatisticamente significantes, comparando com o ano base de 2013, não existindo aqui uma tendência temporal evidenciada, para qualquer tipo de endividamento. A análise do Gráfico 1, já tinha revelado que em termos de endividamento geral, as PME portuguesas evidenciam um padrão relativamente constante desde 2013. As PME do Alentejo revelam similar tendência.

Matias et al. (2015) tinham analisado os efeitos da crise com a utilização de uma variável dummy, comparando os anos pré-crise (2004 a 2007), com os anos da crise (2008 a 2011). Os resultados obtidos mostraram que durante o período da crise, as PME aumentaram o seu endividamento de médio e longo prazo comparativamente com os anos anteriores e diminuíram o nível de endividamento de curto prazo. Já Proença et al. (2014) verificaram uma tendência 
decrescente dos rácios de endividamento das PME nos anos da crise (entre 2007 e 2010). No período temporal aqui considerado, não se detetaram efeitos estatisticamente significativos associados ao tempo.

Comparando os resultados obtidos com os esperados, podemos concluir a existência dos relacionamentos observados na Tabela 8.

Tabela 8 - Relações Esperadas e Observadas entre as Variáveis.

\begin{tabular}{lccccccc}
\hline \multirow{2}{*}{ Hipóteses } & Variáveis & \multicolumn{2}{c}{ Relação Esperada } & \multicolumn{2}{c}{ Relação Observada } \\
\cline { 2 - 8 } & Explicativas & EG & ECP & EMLP & EG & ECP & EMLP \\
\hline $\mathrm{H} 1$ & $\mathrm{OBF}$ & - & - & - & NS & NS & NS \\
\hline $\mathrm{H} 2$ & $\mathrm{RI}$ & - & - & - & $\mathrm{NS}$ & $\mathrm{NS}$ & $\mathrm{NS}$ \\
\hline $\mathrm{H} 3$ & $\mathrm{DIM}$ & + & + & + & + & + & + \\
\hline $\mathrm{H} 4$ & $\mathrm{CA}$ & + & + & + & $\mathrm{NS}$ & - & + \\
\hline $\mathrm{H} 5$ & $\mathrm{RE}$ & + & + & + & - & $\mathrm{NS}$ & $\mathrm{NS}$ \\
\hline $\mathrm{H} 6$ & $\mathrm{RA}$ & - & - & - & - & $\mathrm{NS}$ & - \\
\hline $\mathrm{H} 7$ & $\mathrm{CRE}$ & + & + & + & + & $\mathrm{NS}$ & $\mathrm{NS}$ \\
\hline
\end{tabular}

Nota: "+ "Relação Positiva; " - Relação Negativa; NS - Não Significativa

Fonte: Elaboração própria.

Ao se proceder à análise de cada uma das variáveis independentes, os resultados obtidos através do MEF, permitem concluir o seguinte:

Para as variáveis OBF (outros benefícios fiscais para além da dívida) e RI (risco) não foi possível encontrar evidência estatística que demonstre a influência destas variáveis no endividamento, não se confirmando a $\mathrm{H} 1$ e $\mathrm{H} 2$, para qualquer uma das formas de endividamento. Outros autores tinham chegado a resultados semelhantes relativamente a OBF - Pinho (2013) no que se refere ao EG; Esperança, et al. (2003) no que se refere ao ECP. Em relação ao RI - Vieira \& Novo (2010) no que se refere ao EG e Matias et al. (2015) para o ECP e EMLP, utilizando como proxy do risco a volatilidade dos resultados antes de juros e impostos.

Já no que à variável DIM (dimensão) diz respeito, esta é estatisticamente significativa, confirmando $\mathrm{H} 3$, ou seja, à medida que a dimensão da empresa aumenta também o endividamento aumenta. Da análise das variáveis estudadas, apenas esta variável se mostrou significativa e de sinal esperado, nos três tipos de endividamento. Quanto maior a dimensão de uma empresa, maior tende a ser a dinâmica empresarial e as possibilidades de diversificação do risco, havendo maior facilidade na obtenção de financiamento. Resultados similares foram obtidos na maioria dos estudos empíricos realizados, por exemplo, Serrasqueiro et al. (2011), Proença et al. (2014) e Matias et al. (2015), entre outros.

Relativamente à variável CA (composição do ativo), os resultados são diferentes para os três tipos de endividamento. Em relação ao EG mostra-se sem significância estatística. Já quanto ao ECP, apresenta sinal contrário ao esperado, não se podendo assim confirmar a $\mathrm{H} 4$ para estes dois tipos de endividamento. Na relação com o EMLP, a hipótese colocada de que quanto maior o valor das garantias dos ativos das empresas maior seria o rácio do endividamento, é confirmada pelo resultado obtido. PME que dispõem de ativos fixos tangíveis que possam ser usados como valor colateral, têm maior capacidade de endividamento no médio/longo prazo. PME sem ativos fixos em larga escala têm menos garantias e são forçadas a recorrer a dívidas de curto prazo. Estes resultados estão em linha com os obtidos por outros autores, nomeadamente Sogorb-Mira (2005), Matias et al. (2015) e Matias \& Serrasqueiro (2017), que 
identificaram um efeito negativo da tangibilidade de ativos na dívida de curto prazo, mas positivo na dívida de longo prazo.

No que concerne à variável RE (reputação), na sua relação com o EMLP e o ECP, não se consegue confirmar H5, pois esta não apresenta significância estatística. Apenas em relação ao EG, tem significância estatística mas o sinal é contrário ao esperado, não confirmando H5. No entanto este resultado corrobora a Teoria da Pecking Order, empresas com maior antiguidade, têm maior capacidade de se autofinanciarem via lucros retidos e não necessitam de recorrer a financiamentos externos. Uma relação negativa tinha sido identificada também por Sogorb-Mira (2005) para as PME espanholas, Vos \& Shen (2007) considerando PME da Nova Zelândia e Matias \& Serrasqueiro (2017) para as PME portuguesas no que se refere ao EG. Já Cardoso (2015) identificou esta variável como um importante determinante do endividamento das micro, pequenas e médias empresas do Alentejo, mas com um sinal positivo.

Para a variável RA (rendibilidade do ativo), na sua relação com o ECP esta não revela significância estatística, não se podendo assim confirmar H6. Quanto à sua relação com o EG e com o EMLP, esta é estatisticamente significante e de sinal esperado, confirmando-se assim a H6. Quanto maior for a RA, menor é o recurso das empresas ao financiamento externo, financiando-se estas, via autofinanciamento, tal como o preconizado pela teoria da pecking order. Quanto maior for a capacidade da empresa em gerar lucros, menor é a sua necessidade de recorrer a dívida externa, para financiar a sua atividade e crescimento. De uma maneira geral, os resultados dos estudos empíricos corroboram uma relação negativa entre rentabilidade e dívida, por exemplo, Esperança et al. (2003); Proença et al. (2014), Cardoso (2015) e Serrasqueiro et al. (2011, 2016).

No que respeita a variável CRE (crescimento), apenas para o EG, esta variável apresenta significância estatística (mas apenas a 10\%) apresentando o sinal esperado. Deste modo, a H7 não tem suporte empírico, pelo que não se pode aferir a teoria da pecking order. De forma semelhante também Matias \& Serrasqueiro (2017), tinham verificado que esta variável mostra uma relação positiva com a dívida mas, ou não era estatisticamente significativa ou era pouco significativa.

Foram ainda calculados os coeficientes estandardizados, para aferir que variáveis têm maior "força" explicativa na variável dependente. Podemos verificar pelos valores absolutos que as variáveis mais importantes são a DIM para o ECP e EMLP. Em relação ao EG, as variáveis RE e DIM assumem maior relevância (Tabela 9).

Tabela 9 - Importância das variáveis independentes para a explicação do endividamento

\begin{tabular}{cc}
\cline { 2 - 2 } & EG \\
\hline RE & $-0,4621$ \\
\hline DIM & 0,4614 \\
\hline RA & $-0,1317$ \\
\hline CRE & 0,0337 \\
\hline
\end{tabular}

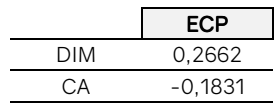

\begin{tabular}{cc}
\cline { 2 - 2 } & EMLP \\
\hline DIM & 0,2684 \\
\hline CA & 0,1838 \\
\hline RA & $-0,1136$ \\
\hline
\end{tabular}

Fonte: Elaboração própria com base nos resultados do STATA 14.

Em resumo, os resultados empíricos obtidos sugerem que os determinantes das decisões de EC das PME da região Alentejo são a dimensão (DIM), a reputação (RE), a tangibilidade (CA) e a rentabilidade (RA) dos ativos. PME com maior antiguidade (como proxy da reputação no 
mercado) e com maior rentabilidade, recorrem menos ao endividamento, corroborando os pressupostos da teoria da Pecking Order.

A terminar, importa confrontar os resultados aqui obtidos com os de Cardoso (2015), que analisou as micro, pequenas e médias empresas da região Alentejo. Enquanto este autor encontrou evidências empíricas que suportam ambas as teorias - Trade-offe Pecking Orderaqui, os resultados sugerem que a teoria da Pecking Orderé a que melhor explica a EC das PME da região Alentejo.

\section{CONCLUSÃO}

Este estudo foi desenvolvido com o objetivo de analisar a EC das PME da região do Alentejo, por forma a identificar qual a teoria preponderante nas decisões de financiamento, bem como, os determinantes da estrutura de capitais das mesmas.

Para a concretização deste objetivo, foram formuladas várias hipóteses com base no exposto na revisão da literatura. Utilizou-se a metodologia de dados em painel, recorrendo a dados relativos às PME da região do Alentejo, no período entre 2013 e 2016. Os dados analisados foram obtidos a partir da base de dados SABI, para um total de 443 empresas.

As variáveis analisadas subdividiram-se em variáveis independentes e dependentes, Como variáveis independentes consideraram-se os outros benefícios fiscais (OBF), o risco (RI), a dimensão (DIM), a composição do ativo (CA), a reputação (RE), a rendibilidade do ativo (RA) e o crescimento (CRE). Como variável dependente, foi considerado o endividamento, sendo considerado o endividamento total (EG), de curto prazo (ECP) e de médio e longo prazo (EMLP).

Pela análise dos valores obtidos em estatística descritiva, aferiu-se que o nível de EG das PME da região do Alentejo, relativo aos anos de 2013 a 2016, situava-se nos 58\%, o ECP situava-se nos $41 \%$ e o EMLP nos $17 \%$. Assim, verificou-se existir uma prevalência do ECP, por parte destas empresas. Durante o período analisado, foi também constatável que as empresas optaram em média, pelo mesmo tipo de endividamento.

A análise dos resultados obtidos na regressão permitiu concluir que a teoria do trade-off não se verifica, dado que a variável OBF se mostra estatisticamente não significativa. Assim, não ficou demonstrado que um aumento no nível de OBF corresponda a um menor nível de endividamento por parte das empresas.

Já a teoria da pecking orderverifica-se relativamente à variável RA, na sua relação com o EG e com o EMLP, com as quais apresenta uma relação negativa e estatisticamente significativa. Conclui-se deste modo, que as empresas mais rentáveis tendem a ter um nível de endividamento reduzido. Tal facto acontece, por as empresas seguirem a hierarquização das fontes de financiamento, recorrendo primeiro às fontes de financiamento internas e só depois às externas. A variável RE também contribui para a explicação desta teoria uma vez que, ao registar uma relação negativa com a variável de EG, permite concluir que as empresas com maior antiguidade recorrem menos ao endividamento externo, pois têm maior capacidade em reter lucros e assim, financiarem-se através de fundos internos.

A variável DIM influencia positivamente a capacidade de endividamento das empresas, uma vez que, empresas maiores apresentam em regra menores riscos de falência e têm maior capacidade de conseguir ter uma situação estável para liquidar os compromissos financeiros assumidos. 
A CA tem uma relação positiva com o EMLP e negativa com o ECP. Esta relação, indica que os ativos fixos tangíveis são usados como garantia na obtenção de financiamento a longo prazo, potenciando assim um aumento deste tipo de endividamento. Com a utilização destes ativos como garantia, são atenuados os problemas de agência com os credores, bem como, os custos de falência. Em caso de necessidade de liquidez, estes bens constituem uma mais-valia que poderá ser usada na negociação com os credores. Empresas que possuam menos ativos fixos tangíveis, menos garantias, terão que utilizar maior ECP.

Em resumo, após a análise dos resultados das várias variáveis, conclui-se que a teoria da pecking orderé aquela que melhor explica a EC das empresas da região do Alentejo, de forma semelhante ao já evidenciado para a generalidade das PME, por estudos anteriores (Tabela 1 e 2). Estas empresas preferem primeiro financiarem-se através de fontes de financiamento internas e só depois recorrer a fontes externas.

Em termos de implicações, os resultados mostraram que empresas mais pequenas tem menor endividamento e quando apresentam menores garantias (menor tangibilidade do Ativo), recorrem mais ao ECP, o que parece evidenciar dificuldades de acesso ao crédito por parte destas empresas. Dada a importância das PME, sugere-se aos decisores políticos, a criação de linhas especiais de crédito e incentivos fiscais para mitigar eventuais dificuldades no acesso a fontes externas de financiamento e promover assim o desenvolvimento e a coesão regional numa das regiões mais desfavorecidas em Portugal. Em períodos de crise, como o associado ao atual contexto pandémico, desencadeado pelo COVID-19, a liquidez das empresas é ainda mais condicionada, tornando o papel do Estado decisivo na mitigação de efeitos nefastos, onde a falta de liquidez, ainda que temporária, pode mesmo acarretar o colapso de micro e pequenas empresas, fonte principal do emprego da região.

Todos os trabalhos apresentam limitações. Aqui, a principal limitação a referir prende-se com a utilização de dados secundários obtidos através da base de dados SABI, sem que tais dados tenham sido cruzados com dados de outras fontes. É que embora as PME sejam legalmente obrigadas a apresentar contas, os referenciais contabilísticos usados podem ser simplificados, conforme indicado no artigo 9o e seguintes do Decreto-Lei n,o 98/2015, de 2 de junho. Além de que os registos contabilísticos nem sempre são objeto de verificação, na medida em que nem todas essas empresas são obrigadas a possuir revisão de contas. Tal situação pode traduzir assim uma limiłação à credibilidade dos dados usados.

Em termos de investigação futura, poderão ser considerados mais anos na análise, incluindo outras variáveis de controlo, nomeadamente a forma jurídica, o setor de atividade e o eventual impacto da nova crise económica gerada pela pandemia COVID-19. Sugere-se ainda, a possibilidade de utilização de uma metodologia mista na recolha dos dados, cruzando as fontes primárias e secundárias.

Por fim, importa realçar que os resultados obtidos no presente estudo são um importante contributo para o aprofundamento do conhecimento da EC das PME da região do Alentejo.

\section{REFERÊNCIAS BIBLIOGRÁFICAS}

Alcarva, P. (2017). O Financiamento Bancário de PME. Coimbra: Actual Editora,

Bradley, M., Jarrell, G. A., \& Kim, E. H. (1984). On the Existence of an Optimal Capital Structure: Theory and Evidence. The Journal of Finance, 39(3), 857-878. https://doi,org/10,2307/2327950

Barañano, Ana M: (2004). Métodos e Técnicas de Investigação em Gestão. Lisboa. Edições Sílabo. 
Cardoso, C. (2015). Estrutura de Capitais das PME Produtoras de Bens Transacionáveis da Região Alentejo - Fatores Determinantes do Endividamento (Dissertação de Mestrado), Universidade de Évora, Évora.

Cervo, A. L. \& Bervian, P. A. (1983). Metodologia Científica. São Paulo. McGraw-Hill.

Correia, L. (2018). Dificuldade das PME(s) obterem Financiamento: Estudo de caso em Portugal (Dissertação de Mestrado), Universidade do Minho, Braga.

Coutinho, Clara P. (2014). Metodologia de Investigação em Ciências Sociais e Humanas. Lisboa: Almedina

Daskalakis, N., \& Psillaki, M. (2008). Do Country or Firm Factors Explain Capital Structure? Evidence From SMEs in France and Greece. Applied Financial Economics, 18(2), 87-97. https://doi,org/10,1080/09603100601018864

Decreto-Lei 98/2015 de 2 de junho. Diário da República n.o 106/2015, Série I. Ministério das Finanças.

Diamond, D. W. (1989). Reputation Acquisition in Debt Markets. Journal of Political Economy, 97(4), 828-862. https://www,jstor,org/stable/1832193

Durand, D. (1952). Costs of Debt and Equity Funds for Business: Trends and Problems of Measurement. Conference on Research in Business Finance, National Bureau of Economic Research, 215-262. http://www.nber.org/chapters/c4790

Esperança, J., Gama, A., \& Azzim Gulamhussen, M. (2003). Corporate Debt Policy of Small Firms: An Empirical (re)examination. Journal of Small Business and Enterprise Development, 10(1), 62-80. https://doi,org/10,1108/14626000310461213

Eurostat (2019). Small and medium-sized enterprises: an overview. Acessível em https://ec.europa.eu/eurostat/web/products-eurostat-news/-/EDN-20191125-

1 ?inheritRedirect=true $\&$ redirect $=\% 2$ Feurostat $\% 2 \mathrm{~F}$

Gama, A. (2000). Os Determinantes da Estrutura de Capital das PMEs Industriais Portuguesas. Série Moderna Finança N.20. Associação da Bolsa de Derivados do Porto.

Gil, A. (2008). Métodos e Técnicas de Pesquisa Social (6a ed.), São Paulo: Atlas.

Gomes, Ricardo (2012). A Estrutura do Capital das Empresas: Teoria ao Longo de 50 anos, Universidade Lusíada, Economia \& Empresa, (14), 119-143.

INE (2019). Anuário Estatístico da Região Alentejo 2018 Statistical Yearbook of Alentejo Region 2018. Lisboa: Instituto Nacional de Estatística, I.P.

INE (2020). Empresas em Portugal 2018. Lisboa: Instituto Nacional de Estatística, I.P.

Jensen, M. \& Meckling, W. C. (1976). Theory of The Firm: Managerial Behavior, Agency Costs and Ownership Structure, Journal of FinancialEconomics, 3(4), 305-360. https://doi, org/10,1016/0304405X(76)90026-X

Jorge, S. \& Armada, M. J. (2001), Factores Determinantes do Endividamento: Uma Análise em Painel. Revista de Administração Contemporânea, 5(2), 9-31. https://doi,org/10,1590/S1415$\underline{65552001000200002}$

Júnior, F. (2012). A Estrutura do Capital das PME'S e das Grandes Empresas: Uma Análise Comparativa (Dissertação de Mestrado). Universidade de Coimbra, Coimbra.

Kim, W. S. \& Sorensen, E. H. (1986), Evidence on the Impact of the Agency Costs of Debt on Corporate Debt Policy. Journal of Financial \& Quantitative Analysis, 21(2), 131-144. https://doi,org/10,2307/2330733

Kraus, A. \& Litzenberger, R. (1973). State Preference Model of Optimal Financial Leverage. The Journal of Finance, 28 (3), 911-922. 
Leland, H. E. \& Pyle, D. H. (1977). Informational Asymmetries, Financial Structure, and Financial Intermediation. The Journal of Finance, 32(2), 371-387. https://doi, org/10,2307/2326770

Marôco, J. (2011), Análise Estatística com o SPSS Statistics (5a ed.), Pero Pinheiro: ReportNumber, Marques, L. (2000). Modelos Dinâmicos com Dados em Painel: Revisão da Literatura. Working paper. Porto: Faculdade de Economia do Porto.

Matias, F., Baptista, C. \& Salsa, L. (2015). Estrutura do Capital das PME da Indústria Transformadora Portuguesa: Uma Análise com Dados em Painel. Tourism \& Management Studies, 11(2), 120-129. https://doi,org/10,18089/tms, 2015,11215

Matias, F. \& Serrasqueiro, Z. (2017), Are there reliable determinant factors of capital structure decisions? Empirical study of SMEs in different regions of Portugal. Research in International Business and Finance, 40, 19-33. https://doi.org/10.1016/j.ribaf.2016.09.014

Matias, F., Salsa, L. \& Afonso, C. (2018). Capital structure of Portuguese hotel firms: a structural equation modelling approach. Tourism \& Management Studies, 14(SI1), 73-82.

Menezes, H. C. (2012). Princípios de Gestão Financeira (13a), Lisboa: Editorial Presença.

Modigliani, F. \& Miller, M. H. (1958), The Cost of Capital, Corporation Finance, and the Theory of Investment. The American Economic Review, 48(3), 261-297. https://www.jstor.org/stable/1809766

Modigliani, F. \& Miller, M. H. (1963). Corporate Income Taxes and the Cost of Capital: A Correction. The American Economic Review, 53(3), 433-443. https://www.jstor.org/stable/1809167

Myers, S. C. (1984). The Capital Structure Puzzle. The Journal of Finance, 39(3), 575-592. https://doi.org/10.1111/j.1540-6261.1984.tb03646.x

Myers, S. C. \& Majluf, N. S. (1984). Corporate Financing and Investment Decisions When Firms Have Information That Investors Do Not Have. Journal of Financial Economics, 13(2), 187-221. https://doi.org/10.1016/0304-405X(84)90023-0

Osteryoung, J., Constand R. L. \& Nast, D. (1992). Financial Ratios in Large Public and Small Private Firms. Journal of Small Business Management, 30(3), 35-46.

Pacheco, L. (2016). Capital structure and internationalization: The case of Portuguese industrial SMEs. Research in International Business and Finance, https://doi.org/38. 10.1016/j.ribaf.2016.07.014.

Pacheco, L. \& Tavares, F. (2015). Capital structure determinants of Portuguese footwear sector SMEs: Empirical evidence using a panel data. Tékhne, 13(2), 145-157.

Park, H. M. (2011). Practical Guides To Panel Data Modeling: A Step-by-step Analysis Using Stata. Tutorial Working Paper. Graduate School of International Relations, International University of Japan.

Pascoal, R. (2008). Diferenças entre pequenas e médias empresas e grandes empresas portuguesas: uma análise empírica dos indicadores económicos e financeiros entre 2001 e 2006 (Dissertação de Mestrado). ISCTE, Lisboa.

Pinho, C. \& Tavares, S. (2005). Análise Financeira e Mercados. Lisboa: Áreas Editora.

Pinho, V. (2013). Financiamento das PME e a Sua Dependência Face ao Crédito Bancário (Dissertação de Mestrado). Universidade de Aveiro, Aveiro.

Proença, P., Laureano, R. M. \& Laureano, L. M. (2014). Determinants of Capital Structure and the 2008 Financial Crisis: Evidence from Portuguese SMEs. Procedia - Social and Behavioral Sciences, 150, 182-191. https://doi.org/10.1016/j.sbspro.2014.09.027

Raposo, F. (2013). O Financiamento e a Performance das PME do Distrito de Castelo Branco (Dissertação de Mestrado). Universidade da Beira Interior, Covilhã.

Recomendação da Comissão no 2003/361/CE de 6 de maio de 2003. Jornal Oficial da União Europeia. 
Ribeiro, C. P. (2015). Os Determinantes da Estrutura Financeira das Empresas Cotadas no PSI Antes e Depois da Crise (Dissertação de Mestrado). Universidade do Porto, Porto.

Rocha, L. M. (2000). Teoria Financeira no contexto das Pequenas e Medias Empresas: o caso do sector têxtil e de vestiário em Portugal (Dissertação de Mestrado). Universidade de Aveiro, Aveiro.

Rogão, M. (2006). Determinantes da Estrutura de Capitais das Empresas Cotadas Portuguesas: Evidência Empírica Usando Modelos de Dados em Painel (Dissertação de Mestrado). Universidade da Beira Interior, Covilhã.

Ross, S. A. (1977). The Determination of Financial Structure: The Incentive-Signaling Approach. The Bel/ Journal of Economics, 8(1), 23-40. https://doi.org/10.2307/3003485

Santos, L. (2016). A Fiscalidade e o Endividamento das Empresas em Portugal (Dissertação de Mestrado). Instituto Superior de Contabilidade e Administração de Coimbra, Coimbra.

Serrasqueiro, Z., Armada, M. R. \& Maças Nunes, P. (2011). Pecking Order Theory Versus Trade-Off Theory: Are Service SMEs' Capital Structure Decisions Different? Service Business, 5(4), 381-409. https://doi.org/10.1007/s11628-011-0119-5

Serrasqueiro, Z., Matias, F. \& Salsa, L. (2016). Determinants of Capital Structure: New Evidence From Portuguese Small Firms. Dosalgarves: A Multidisciplinary e-Journal, 28, 13-28. https://doi.org/10.18089/DAMeJ.2016.28.2

Sibindi, A. (2016). Determinants of capital structure: A literature review. Risk governance \& control: financial markets \& institutions, 6(4-1), 227-237. http://dx.doi.org/10.22495/rcgv6i4c1art13

Silva, A. \& Lopes, C. (2018). Determinantes da Estrutura de capital em empresas industriais exportadoras portuguesas. Revista Egitania Sciencia, 22, 75-93.

Sogorb-Mira, F. (2005). How SME Uniqueness Affects Capital Structure: Evidence From a 19941998 Spanish Data Panel. Small Business Economics, 25(5), 447-457. https://doi.org/10.1007/s11187-004-6486-8

Titman, S. \& Wessels, R. (1988). The Determinants of Capital Structure Choice. The Journal of Finance, 43(1), 1-19. https://doi.org/10.1111/j.1540-6261.1988.tb02585.x

Vieira, E. \& Novo, A. (2010). A Estrutura de Capital das PME: Evidência no Mercado Português. Revista de Estudos do ISCA, (№2).

Vos, E. \& Shen, Y. (2007). The Happy Story Told by Small Business Capital Structure. SSRNElectronic Journal. https://doi.org/10.2139/ssrn.1000293

Wooldridge, J. M. (2015). Introductory Econometrics: A Modern Approach. 5th Edition, Mason, Ohio: South-Western Cengage Learning. 


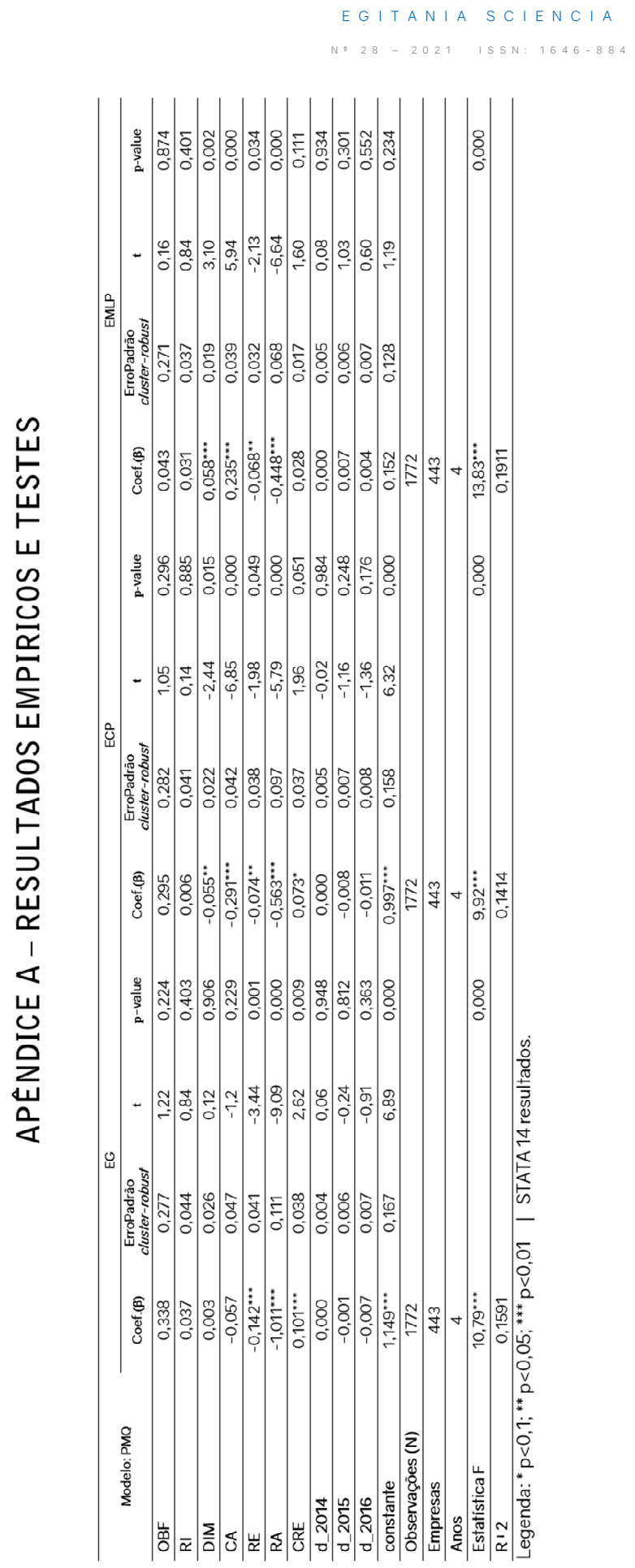




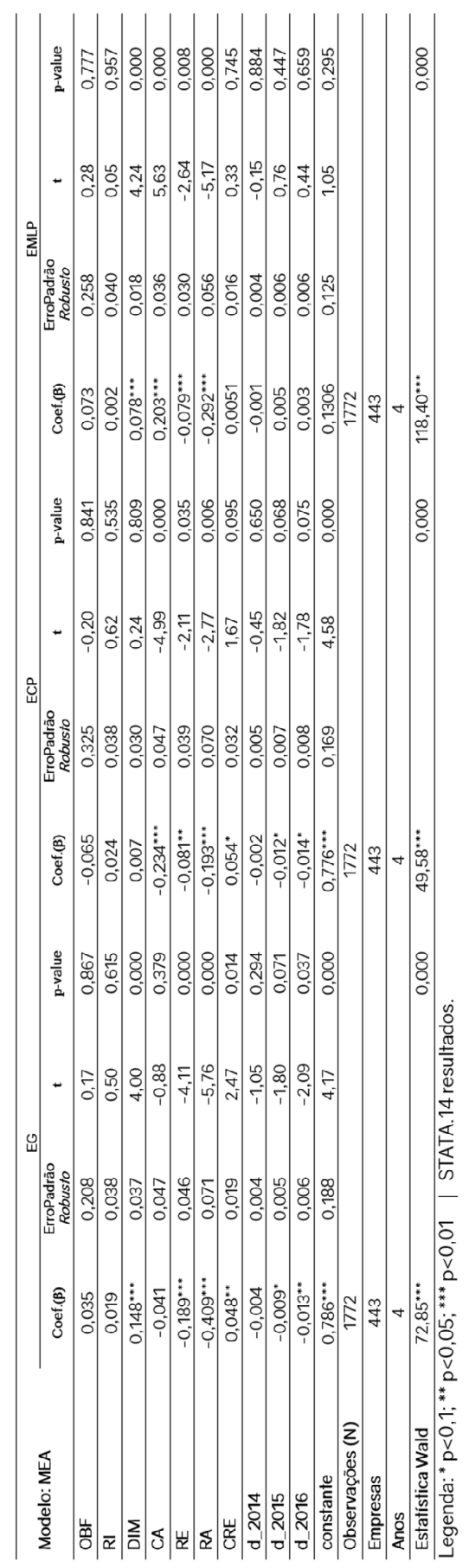


Comparação entre os modelos (Park, 2011)

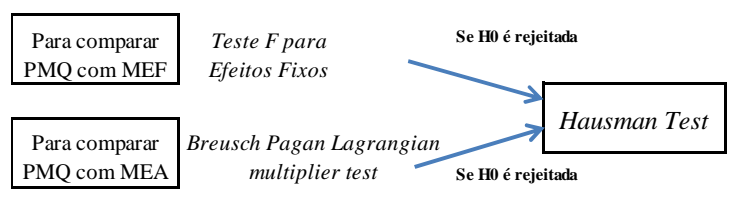

Resultados:

\begin{tabular}{cccc}
\hline & Efeitos Fixos & Efeitos Aleatórios & \multirow{2}{*}{ Teste de Hausman } \\
\hline \multirow{2}{*}{ EG } & (F-test) & (B-P LM test) & 103,29 \\
& 40,20 & 2025,29 & $(0,0000)$ \\
\hline \multirow{2}{*}{ ECP } & $(0,0000)$ & $(0,0000)$ & 49,82 \\
& 16,47 & 1598,61 & $(0,0000)$ \\
\hline \multirow{2}{*}{ EMLP } & $(0,0000)$ & $(0,0000)$ & 17,54 \\
& 12,70 & 1450,38 & $(0,0000)$ \\
\hline
\end{tabular}

Fonte: STATA 14 resultados.

Para todas as regressões, o teste $\mathrm{F}$ de Efeitos Fixos leva à Rejeição de $\mathrm{HO}$, o que leva à conclusão que o MEF é preferível ao PMQ;

Para todas as regressões, o teste B-P LM conduz à Rejeição de HO, o que permite concluir que o MEA é preferível ao PMQ;

Comparando o MEA com o MEF, os valores do teste de Hausman levam à rejeição de $\mathrm{HO}$, sendo mais adequada a opção pelo MEF. 